\title{
A Drink Best Not Served: Conflicts of Interests When the Alcohol Industry Seeks To Inform Public Health Practice and Policy
}

Anna Piazza-Gardner* and Adam E. Barry

University of Florida, Gainesville, FL, USA

\begin{abstract}
The inherent contrast between the priorities of public health and the goals of for-profit companies becomes overwhelmingly obvious when examining the "public health" efforts/policies for-profit industries support and oppose. The purpose of this commentary is to highlight the divergent goals of public health and for-profit industry, as well as the risks associated with collaboration between public health and for-profit entities. Ongoing alcohol industry-supported endeavors, such as wait-staff training, alcohol education programs, and promotional advertising, are presented as heuristic examples. By collaborating with the alcohol industry, public health officials and organizations become more willing to compromise standards and adopt values of the industry, and less likely to oppose values, operations, and products of the industry. The heuristic examples provided make overwhelmingly clear, advertising, partnerships, and program involvement by the alcohol industry are only intended to sell more alcohol.
\end{abstract}

\section{Background}

The overall goal of public health is to promote societal health and well-being by enacting organized efforts aimed at preventing disease and prolonging life $[1,2]$. Conversely, the overarching goal of forprofit business is growth and monetary gain. This inherent contrast becomes overwhelmingly obvious when examining the "public health" efforts/policies for-profit industries support and oppose. For instance, in-person semi-structured interviews with alcohol-industry representatives characterize the industry's vehement opposition [3] to proven, effective strategies such as increasing the monetary price of alcohol (i.e., higher taxes) [4]. Additionally, the alcohol industry has long supported designated driver campaigns/programs [5], despite the lack of systematic evidence indicating their effectiveness at reducing alcohol-impaired driving or alcohol-related consequences [6]. As Miller, de Groot, McKenzie \& Droste [7] contend, "the [alcohol] industry has invested massive resources in a global effort to produce a light-touch self-regulatory environment that favours its commercial interests while allowing industry members to represent themselves as 'responsible' corporate citizens"' ( $\mathrm{p} 1560)$.

The purpose of this commentary is to highlight the divergent goals of public health and for-profit industry, as well as the risks associated with collaboration between public health and for-profit entities. In order to accomplish these objectives, several recent and ongoing alcohol industry-supported endeavors, both educational and promotional, will be presented as heuristic examples. Current scientific knowledge will be used to provide context to all presented examples. Furthermore, we will conclude with a summative commentary highlighting how industry-backed promotions/initiatives/activities can be detrimental to the overall goals of public health.

\section{Educational and Training Programs}

\section{Wait staff training}

Throughout both the United States and Canada, companies such as ProServe (Canada) and TIPS (Training for Intervention Procedures; U.S.) [8] offer liquor staff training/certifications for bartenders, servers, and owners of licensed liquor establishments. In general, this training is designed to aid in the prevention of underage drinking, overconsumption of alcohol, impaired driving, and alcohol-related violence by teaching wait and bartending staff responsible service strategies and how to visually identify intoxicated patrons $[9,10]$.
Currently, alcohol industry entities such as Wine \& Spirits Wholesalers of America, Inc. (WSWA) are partnered with the national overseer of TIPS (Health Communications, Inc.; HCI)) to train and certify WSWA employees so they can, in turn, train retail staff on TIPS techniques for serving alcohol safely. Ignoring the conflict of interest present between such partnerships, it is no surprise alcohol entities would support such programs. After all, no group of trained (physicians, bartenders) or untrained (laypersons, college students) persons can consistently and accurately determine alcohol-related impairment without access to specialized instruments (i.e. breathalyzer) and prescribed testing (i.e., standardized field sobriety tests) [11]. Research documents mixed results regarding wait-staff training effectiveness for identifying intoxication and using intervention strategies [12]. Moreover, previous studies suggest that wait-staff denying service to intoxicated patrons is rare [13-16].

\section{Alcohol 101}

Alcohol 101 Plus is funded by The Century Council, comprised of America's leading distillers, who, as of 1991, report investing nearly $\$ 175$ million into the program [17]. In general, this "virtual" CDROM-based initiative is designed to help college students make "safe and responsible decisions about alcohol" and reduce deleterious consequences of alcohol misuse and abuse [18]. At face value, these efforts appear efficacious however, formal reviews reveal no significant differences between Alcohol 101 and traditional educational programs [19]. Reviews of similar programs have also documented general ineffectiveness at reducing alcohol-related harm [20]. While the evidence-base for any internet-based alcohol prevention program

*Corresponding author: Anna Piazza-Gardner, Doctoral Student, University of Florida, Health Education and Behavior, P.O. Box 118210, Gainesville, FL 32611 8210, USA, Tel: 1-989-798-0240; E-mail: akgardner@ufl.edu

Received October 21, 2011; Accepted December 06, 2011; Published December 12, 2011

Citation: Piazza-Gardner A, Barry AE (2011) A Drink Best Not Served: Conflicts of Interests When the Alcohol Industry Seeks To Inform Public Health Practice and Policy. J Clin Res Bioeth S4:001. doi:10.4172/2155-9627.S4-001

Copyright: (C) 2011 Piazza-Gardner A, et al. This is an open-access article distributed under the terms of the Creative Commons Attribution License, which permits unrestricted use, distribution, and reproduction in any medium, provided the original author and source are credited. 
(e.g., AlcoholEdu, e-CHUG, myStudentBody) is still in its infancy, the overwhelming majority suggest only a short-term positive impact from these efforts [21-23].

\section{Norms restructuring campaigns}

Industry-funded "social norms" alcohol awareness programs are designed to decrease campus alcohol consumption through advertisements (e.g., posters, public service announcements, flyers) suggesting evidence-based average alcohol consumption levels [2426]. For example, a social norms message may be something along the following lines: "Most people only drink an average of two-three drinks in a week". Most typically implemented on college campuses, social norms campaigns are built on the assumption that college students overestimate the drinking levels (frequency and quantity) of their peers $[27,28]$. Since the perceived drinking level of peers positively correlates to personal alcohol consumption [29,30], it is believed students drink to what they perceive to be normal. Wechseler et al. [31] contend social norms campaigns are appealing to the alcohol industry because they a) fail to emphasize the negative consequences of heavy drinking, and b) downplay the level of drinking on campuses. In a longitudinal comparison of 37 schools utilizing social norms campaigns and 61 schools without social norms programs, there was no significant difference in drinking behaviors across frequency, quantity, drunkenness or heavy episodic drinking [31]. Some quasiexperimental evaluations have actually documented increased drinking associated with social norm programs [32].

\section{Promotional and Advertising Campaigns}

\section{"Safe" levels of drinking}

As early as the 1980s, health official coined the term "safe" level of drinking, following endorsements by National Health and Medical Research Council [33]. Eventually, support for these recommendations lessened as experts became reluctant to recommend any level of drinking as inherently "safe", recognizing the message could be misinterpreted as suggesting individuals should drink up to those levels [34]. Furthermore, guidelines for "safe" or "sensible" drinking often fail to recognize that many people (e.g., pregnant women, recovering alcoholics, prior to operating a motor vehicle) should refrain from drinking completely [35]. Nevertheless, the alcohol industry continues to support and contribute to the development of "low-risk" drinking levels [36].

\section{Responsible drinking}

Currently, the alcohol industry has entrenched their marketing efforts within a "responsible drinking" context. As a whole, these efforts typically center upon encouraging drinkers to refrain from drinking and driving [37]. Since 1982, Anheuser-Busch reports investing more than $\$ 675$ million in responsibility campaigns, alcohol awareness, and education programs - an average of 27 million per year. For 2006 alone, however, Anheuser -Busch spent $\$ 22.5$ million on Super Bowl advertising airtime, not including advertisement production costs [38]. Between the years of $2001-2007$, alcohol companies spent 43 times as much on product advertisements than responsibility messages [39]. Critical examination reveals alcohol industry-sponsored responsible drinking advertisements a) project pro-drinking themes [5], b) are strategically ambiguous in nature [40], c) lack unity between the visuals and verbal message [5], while at the same time convincing viewers that sensible advice is being provided [41]. In fact, Barry [42] contends responsible drinking promotions may actually provide dissonant individuals (i.e., those feeling anxiety about one's drinking behaviors) alleviation through consistent exposure to visual imagery employed in these advertisements. Overall, researchers characterize responsible drinking campaigns/promotions as amalgams of "commercial, public relations, and public service persuasion strategies" [43]. Smith, Atkin \& Roznowski [40] contend more accurate labels for responsible drinking campaigns would be "private service messages" (p1).

\section{The health benefits of drinking}

Recently, the alcohol industry has begun to market alcoholic beverages as "healthy" or "diet-friendly". With the rise in popularity of carb-conscious diets, such as Atkins, the alcohol industry has responded with an increase in low-carb beer offerings [44]. Through the use of health buzzwords like "fortified", "antioxidant", "light", "low-carb", and "all-natural", company advertisements are keying in on health- and weight-conscious consumers [45]. Unfortunately, little scientific evidence is available to support the applicability of such claims. For instance, the Marin Institute (2011) contends such claims represent false-advertising in that "only the company's descriptions of the products seem to have changed" (page 6). In other words, "allnatural" and "low-carb" beers contain the same composition and ingredients as other, presumably less healthy, alcoholic offerings.

In the past, alcohol producers and distributors swooned over research suggesting potential health benefits of daily alcohol consumption [46], employing slogans such as "Drink to your health" to suggest consumption as both socially acceptable and beneficial to health [47]. While prior research has identified decreased risk of cardiovascular disease with low-level alcohol use ( 2 drinks per day or fewer), these findings have been reconciled when considering the "quality" of the investigations [48]. Thus, the relative quality of investigations supporting health benefits of drinking were found to strongly influence the dose-effect relationship, leading researchers to conclude "the degree of any protective effect due to moderate doses of alcohol should be reconsidered" [48].

\section{Fan cans}

In conjunction with the 2009 United States' National College Athletics Association's college football season, Anheuser-Busch unveiled the "fan can" promotion [49]. In general, this marketing promotion consisted of decorating Bud Light cans with the colors of several college football teams. In addition to the Federal Trade Commission, many colleges immediately protested, requesting omission from the "fan can" promotion [50,51]. Detractors were primarily concerned that the promotion was unduly aimed at underage drinkers, who account for approximately $11 \%$ of alcohol consumed in the U.S. [52]. In response, Anheuser-Busch claimed it would abort promotion of the product in the community if a college complains; however, when Boston College submitted a letter objecting to the use of its school colors, Anheuser-Busch asserted that it had the right to market its product using the colors [53]. To avoid further dispute, the beer company agreed to discontinue production and promotion of products using such color combinations. Unfortunately, many colleges still allow the "fan can" to invade their communities and boost company sales.

\section{Promotion of underage drinking}

In 2002, an Australian-based public health group [Alcohol and Drug Foundation - Queensland (ADFQ)] formed a partnership with the liquor industry to promote responsible, moderate alcohol consumption [54]. Not long after forming the organization, the partnered liquor industry submitted an application for a new alcoholic beverage, Moo 
Joose to Liquor Licensing Victoria (LLV), the state licensing authority. Moo Joose was a $5 \%$ alcohol by volume product intended to mimic flavored milk and would be sold in flavors of chocolate, banana, strawberry, and coffee. In their decision to ultimately reject the product application, LLV asserted that Moo Joose posed risks to underage drinking by appearing overly attractive to children [55]. Looking to the ADFQ for advice, the product manufacturer (Wicked Holdings Pty Ltd) was instructed to adjust the product appearance and marketing strategy, while changing the name to Alcoholic Moo Joose [56]. By ultimately supporting the product, the decision ADFQ ran counter to previous policies prohibiting Candy Shots, a vodka drink marketed in flavors of chocolate, banana, caramel, and marshmallow [57].

As is clear in both instances (Moo Joose \& Candy Shots), the targets of such a product are underage drinkers. This is concerning considering the growing body of scholarly literature indicating a positive association between youth drinking behaviors and exposure to alcohol advertising [58-60]. In 2003, the Center on Alcohol Marketing and Youth reported that for every ad referring to the legal drinking age, there were 179 product ads aimed at underage drinking. This should come as no surprise, as "today's underage drinkers are tomorrow's legitimate customers" [61]. Of the total annual consumer expenditures on alcohol, economic estimates attribute $\$ 22.5$ billion (17.5\% of all expenditures) to underage drinkers [62].

\section{Conclusion}

As the heuristic examples outlined above clearly demonstrate, the goals of the alcohol industry run counter to that of public health. The organized efforts (educational and promotional) enacted by the alcohol industry are not grounded in, or supported by, current scientific literature documenting effective/best practice. Moreover, the advertising activities, partnerships, and program development/ involvement in which the alcohol industry engage are only intended to sell more alcohol. Consequently, these efforts fail to contribute to the overall goals of public health to either prevent disease and/or prolonging life $[1,2]$. As a result, public health officials researchers and practitioners should consider the alcohol industry a wolf in sheep's clothing. The evidence presented herein demonstrates how the role they are playing (attempting to positively impact the health and welfare of the public), is contradictory to their basic character/nature (dedicated to profit and monetary gain). By collaborating with the alcohol industry, public health official and organizations become more willing to compromise standards and adopt values of the industry, and less likely to oppose values, operations, and products of the industry $[63,64]$. When organizations become dependent on corporate funds, the industry continually gains further power over that organization. As one public health activist participating in Kaskutas' (2004) qualitative investigation incisively articulated, partnership with the alcohol industry is "not an issue of collaboration, it's an issue of negotiation... because we are at odds in terms of the underlying purposes" (p660).

\section{References}

1. Institute of Medicine (1988) The future of public health. Washington, DC: National Academy Press.

2. Public Health Leadership Society (2002) Principles of the Ethical Practice of Public Health, Version 2.2.

3. Kaskutas LA (2004) Division in the ranks: An analysis of alliances and dissension in the alcohol industry and communities. Contemporary Drug Problems advocacy 31: 655-672.

4. Chaloupka FJ, Grossman M, Saffer H (2002) The effects of price on alcohol consumption and alcohol-related problems. Alcohol Res Health 26: 22-34.
5. DeJong W, Wallack, $L$ (1992) The roles of designated driver programs in the prevention of alcohol-impaired driving: A critical reassessment. Health Educ $Q$ 19: $429-442$

6. Ditter SM, Elder RW, Shults RA, Sleet DA, Compton R, et al. (2005) Effectiveness of designated driver programs for reducing alcohol-impaired driving. Am J Prev Med 28: 280-287.

7. Miller PG, de Groot F, McKenzie S, Droste N (2011) Alcohol industry use of special aspect public relations organizations against preventative health measures. Addiction 106: 1560-1567.

8. TIPS - Training for Intervention Procedures (August 8, 2008) Wine and spirits wholesalers of America partners with health communications to bring alcoho training to communities. Press Release.

9. Professional Bartending Schools of America, Inc. (2009) TIPS alcohol training online.

10. Alberta Gaming and Liquor Commission (2011) ProServe liquor staff training.

11. Rubenzer S (2011) Judging intoxication. Behavioral Sciences and the Law 29 116-137

12. Burns ED, Nusbaumer MR, Reiling DM (2003) Think they're drunk? Alcohol servers and the identification of intoxication. J Drug Educ 33: 177-186.

13. Andreasson G, Lindewald B, Rehnman C (2000) Over-serving patrons in licensed premises in Stockholm. Addiction 95: 359-364.

14. McLean S, Wood LJ, Davidson J, Montgomery IM, Jones ME (1993) Alcoho consumption and driving intentions amongst hotel patrons. Drug Alcohol Rev 12: $23-36$.

15. Rydon P, Stockwell T, Syed DA, Jenkins EM (1993) Blood alcohol levels of patrons leaving licensed premises in Perth, Western Australia. Aust J Public Health 17: $339-345$.

16. Rydon P, Stockwell T, Lang E, Beel A (1996) Pseudo-drunk patron evaluation of bar-staff compliance with Western Australian liquor law. Aust N Z J Public Health 20: 290-295.

17. The Century Council (2011) Alcohol 101 plus.

18. Riley WL (1998) Alcohol 101: A CD-Rom program for education students about the consequences of drinking. About Campus 3: 22-24.

19. Donohue B, Allen DN, Maurer A, Ozols J, Giuliana D (2004) A controlled evalutation of two programs in reducing alcohol use among college students at low and high risk for alcohol related problems. Journal of Alcohol \& Drug Education 48: 13-33.

20. The Marin Institute (2009) Why educational strategies are ineffective. The Marin Institute Report: 1-2.

21. Hustad JTP, Barnett NP, Borsari B, Jackson KM (2010) Web-based alcoho prevention for incoming college students: A randomized controlled trial. Addict Behav 35: 183-189.

22. Paschall MJ, Antin T, Ringwalt CL, Saltz RF (2011a) Effects of AlcoholEdu for college on alcohol-related problems among freshmen: A randomized multicampus trial. J Stud Alcohol Drugs 72: 642-650.

23. Paschall MJ, Antin T, Ringwalt CL, Saltz RF (2011b) Evaluation of an internetbased alcohol misues prevention course for college freshmen: Finding from a randomized multi-campus trial. Am J Prev Med 41: 300-308.

24. The Health Reformer (2002) "Social norms" alcohol awareness programs touted by the liquor industry- have not only failed to reduce student drinking, but may have increased it.

25. Rice R, Haines MP (2003) Social norms: A publicly funded, cost-effective approach. The National Social Norms Research Center.

26. Harvard School of Public Health (2005) A matter of degree: Evaluating environmental prevention approaches to alcohol abuse by college students.

27. Borsari B, Carey KB (2003) Descriptive and injunctive norms in college drinking A meta-analytic integration. J Stud Alcohol64: 331-341.

28. Perkins HW, Meilman PW, Leichliter JS, Cashin JR, Presley CA (1999) Misperceptions of the norms for the frequency of alcohol and other drug use on college campuses. J Am Coll Health 47: 253-258.

29. Baer JS, Carney MM (1993) Biases in the perceptions of the consequences of alcohol use among college students. J Stud Alcohol 54: 54-60. 
Citation: Piazza-Gardner A, Barry AE (2011) A Drink Best Not Served: Conflicts of Interests When the Alcohol Industry Seeks To Inform Public Health Practice and Policy. J Clin Res Bioeth S4:001. doi:10.4172/2155-9627.S4-001

Page 4 of 5

30. Perkins HW, Wechsler H (1996) Variation in perceived college drinking norms and its impact on alcohol abuse: A nationwide study. Journal of Drug Issues 26: $961-974$

31. Wechsler H, Nelson TF, Lee JE, Seibring M, Lewis C, Keeling R (2003) Perception and reality: a national evaluation of social norms marketing interventions to reduce college students' heavy alcohol use. J Stud Alcohol 64: 484-494

32. Clapp JD, Lange JE, Russell C, Shillington A, Voas RB (2003) A failed norms social marketing campaign. J Stud Alcohol 64: 409-414.

33. Hawks D (1992) Lying down with the lion: co-operating with the alcoho industry? The 1991 Leonard Ball Oration. Drug Alcohol Rev11: 51-58.

34. Bradley KA, Donovan DM, Larson EB (1993) How much is too much? Advising patients about safe levels of alcohol consumption. Arch Intern Med 153: 2734 2740 .

35. Latino-Martel P, Arwidson P, Ancellin R, Druesne-Pecollo N, Hercberg S, et al. (2011) Alcohol consumption and cancer rusk: Revisiting guidelines for sensible drinking. CMAJ 183: 1861-1865

36. Canadian Low-Risk Alcohol Guidelines Expert Advisory Panel (2010) Alcoho and Health in Canada: A Summary of Evidence and Guidelines for Low-Risk Drinking

37. Barry AE, Goodson P (2010) Use (and misuse) of the responsible drinking message in public health and alcohol advertising: A review. Health Education \& Behavior 37: 288-303.

38. Center for Science in the Public Interest (2008) Alcohol Policies Project: Fact Sheet. Putting Anheuser Busch's consumer responsibility campaign into perspective.

39. Center on Alcohol Marketing and Youth (2008) Youth exposure to alcoho advertising on television, 2001 to 2007. Washington DC: Author, Georgetown University

40. Smith SW, Atkin CK, Roznowski J (2006) Are "drink responsibly" alcoho campaigns strategically ambiguous? Health Commun 20: 1-11.

41. Atkin C, Smith S, Bang HK (1994) How young viewers respond to televised drinking and driving messages. Alcohol. Drugs and Driving 10: 263-275.

42. Barry AE (2007) A theory-based commentary on the hypothesized impact of alcohol industry-sponsored responsible drinking campaigns. The Health Education Monograph Series 24: 1-4.

43. Agostinelli G, Grube, JW (2002) Alcohol counter-advertising and the media: A review of recent research. Alcohol Research \& Health 26: 15-21.

44. Howard T (2003) Atkins diet inspires low-carb beers. USA Today.

45. Simon M, Brancolini J, Treffers R (2011) Questionable health claims by alcohol companies: from protein vodka to weight-loss beer. The Marin Institute Report $1-17$.

46. Moore R, Pearson T (1986) Moderate alcohol consumption and coronary artery disease. Medicine 65: 242-267.

47. Pearson H (2004) The demon drink. Nature 428: 598-600

48. Corrao G, Rubbiati L, Bagnardi V, Zambon A, Poikolainen K (2000) Alcohol and coronary heart disease: a meta-analysis. Addiction 95: 1505-1523.

49. Barry AE (2009) Alcohol advertisers true colors on display with fan can promotion. Journal of Alcohol \& Drug Education 26: 15-21.

50. Hechinger J (2009) FTC criticizes college-themed can in Anheuser-Busch marketing efforts. The Wall Street Journal p. B1.

51. Kever J (2009) Bud Light fan can promo losing its fizz. Houston Chronicle.

52. Office of Juvenile Justice and Delinquency Prevention (2005) Drinking in America: Myths, Realities, and Prevention Policy. Washington, DC: US Department of Justice, Office of Justice Programs, Office of Juvenile Justice and Delinquency Prevention.

53. Blackistone K (2009) Bud Light 'fan can' brewing up trouble. AOL News

54. Alcohol and Drug Foundation- Queensland (ADFQ) (2002) Alcohol Education Australia Ltd. Brisbane: ADFQ.

55. Kearney B (2002) Reasons for decision to refuse application no. 35556, dated 9 August by Wicked Holdings Pty Ltd for a pre-retail license. Melbourne: Liquor Licensing Victoria.
56. Gosling A (2003) Alcoholic Moo Joose bunfight highlights hypocrisy. Drugs in Society March: 14-15.

57. Gold Coast Bulletin (1997) Sweet alcohol danger to kids. Gold Coast Bulletin May 16: 5.

58. Austin EW, Knaus C (2000) Predicting the potential for risky behavior among those "too young" to drink as the result of appealing advertising. Journal of Health Communication 5: 13-27.

59. Unger JB, Schuster D, Zogg J, Dent CW, Stacy AW (2003) Alcohol advertising exposure and adolescent alcohol use: A comparison of exposure measures. Addiction Research and Theory 11: 177-193.

60. Collins RL, Schell T, Ellickson P, McCaffrey D (2003) Predictors of beer advertising awareness among eighth graders. Addiction 98: 1297-1306

61. Bonnie RJ, O'Connell ME (Eds) (2004) Reducing underage drinking: A collective responsibility. Washington DC: The National Academies Press.

62. Foster SE, Vaughan RD, Foster WH, Califano JA (2006) Estimate of the commercial value of underage drinking and adult abusive and dependent drinking to the alcohol industry. Archives of Pediatrics \& Adolescent Medicine 160: $473-478$.

63. Wiist B (2011a) The risks to public health from partnerships with corporations Corporations and Health Watch.

64. Wiist B (2011a) Philanthropic foundations and the public health agenda Corporations and Health Watch.

65. American Academy of Pediatrics (1995) Children, adolescents, and advertising Pediatrics 95: 295-297.

66. BayhDole25, Inc. (2006) The Bayh-Dole act at 25. New York.

67. Blumenthal D, Campbell EG, Causino N, Louis KS (1996) Participation of lifescience faculty in research relationships with industry. N Engl J Med 335: 1734 1739

68. Blumenthal D (2003) Academic-industrial relationships in the life sciences. N Engl J Med 349: 2452-2459.

69. Blumenthal D (2004) Doctors and drug companies. N Engl J Med 351: 18851890

70. Center on Alcohol Marketing and Youth (2002) Overexposed: Youth a targe of alcohol advertising in magazines. Washington DC: Author, Georgetown University.

71. Center on Alcohol Marketing and Youth (2003) Drops in the bucket: Alcohol industry "responsibility" advertising on television in 2001. Washington, DC: Author, Georgetown University.

72. Christie J, Fisher D, Kozup JC, Smith S, Burton S, Creyer EH (2001) The effects of bar-sponsored alcohol beverage promotions across binge and nonbinge drinkers. J Public Pol Marketing 20: 240-253.

73. Cosgrove L, Krimsky S, Vijayaraghavan M, Schneider L (2006) Financia ties between DSM-IV panel members and the pharmaceutical industry. Psychotherapy and Psychosomatics 75: 154-160.

74. Hawks D (1989) Is it possible to recommend safe drinking levels without increasing per capita consumption? Another aspect of the prevention paradox. British Journal of Addiction 84: 371-375.

75. Jahiel R, Babor T F (2007) Industrial epidemics, public health advocacy and the alcohol industry: lessons from other fields. Addiction, 102: 1335-1339.

76. Jones L, James M, Jefferson T, et al. (2007) A review of the effectiveness and cost-effectiveness of interventions delivered in primary and secondary schools to prevent and/or reduce alcohol use by young people under 18 years old. Alcohol and schools: review of effectiveness and cost-effectiveness. NICE: main report (PHIAC 14.3a)

77. Kerber R (2004) Drug makers target consumers with their ads. Boston Globe March 10: C1.

78. Soares A, Aldred R (2003) Report to Anthony P. Sofra. Brisbane: Alcohol \& Drug Foundation- Queensland.

79. Swann JP (1988) Academic scientists and the pharmaceutical industry cooperative research in twentieth-century America. Baltimore: Johns Hopkins University Press.

80. Steinbrook R (2004) Financial conflicts of interest and the NIH. N Engl J Med 350: $327-330$ 
Citation: Piazza-Gardner A, Barry AE (2011) A Drink Best Not Served: Conflicts of Interests When the Alcohol Industry Seeks To Inform Public Health Practice and Policy. J Clin Res Bioeth S4:001. doi:10.4172/2155-9627.S4-001

Page 5 of 5

81. Tereskerz PM Moreno J (2005) Ten steps to developing a national agenda to address financial conflicts of interest in industry sponsored clinical research. Accountability in Research 12: 139-155.
82. Wazana A (2000) Physicians and the pharmaceutical industry: is a gift ever jus a gift? JAMA 283: 373-380.

This article was originally published in a special issue, Ethics: Public Health handled by Editor(s). Dr. Kristine Bcerøe, University of Bergen, Norway 